\title{
RECÉM-NASCIDO EM UMA UNIDADE DE INTERNAÇÃO NEONATAL: CRENÇAS E SENTIMENTOS MATERNOS
}

Mirna Albuquerque Frota ${ }^{1}$, Antônia do Carmo Soares Campos $^{2}$, Zeferina Bezerra Pimentel ${ }^{3}$, Cinthia Maria Gomes da Costa Escoto Esteche ${ }^{4}$

\begin{abstract}
RESUMO: Este é um estudo exploratório e descritivo com abordagem qualitativa com os objetivos de: conhecer o significado do ambiente da Unidade de Internação Neonatal para as mães dos recém-nascidos e identificar as crenças e os sentimentos das mães ante o recém-nascido internado em uma Unidade de Internação Neonatal. Foi realizado na UIN de um hospital público de grande porte em Fortaleza-CE. Os sujeitos foram 11 mães de RN internados na UIN do referido hospital. Os dados foram coletados em agosto e setembro/2005 por meio de entrevista semi-estruturada. $\mathrm{Na}$ análise dos dados identificou-se as categorias: unidade de internação neonatal, sentimento em relação ao internamento de seu filho na UIN, orientações recebidas $\mathrm{x}$ aparato tecnológico e recepção na unidade de internação neonatal. Concluiu-se que a ausência de informações relativas o estado de saúde do bebê, procedimentos e aparelhos presentes na UIN pode causar o afastamento da mãe da unidade e, conseqüentemente, do seu filho.
\end{abstract}

PALAVRAS-CHAVE: Recém-nascido; Neonatologia; Enfermagem.

\section{NEWBORN AT A NEONATAL CARE UNIT: MATERNAL BELIEFS AND FEELINGS}

ABSTRACT: This is a descriptive exploratory study, qualitative approach, aiming to: know the meaning of the Neonatal Care Unit NCU setting for mothers of newborns and identify their beliefs and feelings towards their children admitted to a Neonatal Care Unit. It was carried out in the Neonatal Care Unit of a large public hospital in Fortaleza, Ceara State/ Brazil. The subjects were 11 mothers of newborns hospitalized in the Neonatal Care Unit of the aforementioned hospital. Data were collected in August and September/2005 by means of a semi-structured interview. In the data analysis, the following categories were identified: neonatal care unit, feeling concerning their children's hospitalization in the Neonatal Care Unit, received guidance $\mathrm{x}$ technological apparatus and reception in the Neonatal Care Unit. It was concluded that: the lack of information about the baby's health condition, procedures and devices present in the Neonatal Care Unit may cause the mother's detachment from the unit and, consequently, from her child.

KEYWORDS: Newborn; Neonatology; Nursing.

\section{RECIÉN NACIDO EN LA UNIDAD DE NEONATOLOGÍA - CREENCIAS Y EMOCIONES MATERNALES}

RESUMEN: Objetivos: conocer el significado del ambiente de la Unidad de Neonatología para las madres de los RNs e identificar las creencias y los sentimientos de las madres delante del recién nacido hospitalizado en una Unidad de Neonatología. Métodos: investigación exploratoria y descriptiva con abordaje cualitativa. La investigación fue realizada en la Unidade de Neonatología de un hospital público de gran importancia en Fortaleza - CE. Los sujetos fueron 11 madres de recién nacidos hospitalizados en la Unidade de Neonatología del referido hospital. Los datos fueron colectados en agosto y septiembre/2005 a través de entrevista estructurada en parte. Resultados: en el análisis de fragmentos de discursos de las participantes, se identificó las categorías: unidad de internación neonatal, emoción con relación al ingreso hospitalario de su hijo en la Unidade de Neonatogía, orientaciones recebidas x recursos tecnológicos y recepción en la unidad de internación. Conclusión: la falta de informaciones con respecto al estado de salud del niño, procedimientos y aparatos en la Unidade de Neonatología pueden causar el alejamiento de la madre de la unidad y, por consecuencia, de su hijo.

PALABRAS CLAVE: Recién nacido; Neonatología; Enfermería.

'Enfermeira. Professora Doutora do curso de Graduação em Enfermagem e do Mestrado em Educação em Saúde. Universidade de Fortaleza UNIFOR.

${ }^{2}$ Enfermeira. Professora Doutora do Curso de Graduação em Enfermagem da UNIFOR.

${ }^{3}$ Enfermeira da UNIFOR

${ }^{4}$ Mestre em Enfermagem. UNIFOR.

Autor correspondente

Mirna Albuquerque Frota

Rua Manoel Jacaré, 150, apto 1401, 60175-110 - Fortaleza - Ceará Recebido:17/11/2007

Email: mirnafrota@unifor.br 


\section{INTRODUÇÃO}

É inquestionável que a evolução da tecnologia modificou o prognóstico e a sobrevida dos recémnascidos (RN). A neonatologia é um campo vasto, em desenvolvimento, sendo na atualidade sinônimo de pesquisa e assistência, sua principal meta é a redução da morbidade e da mortalidade perinatais e a busca de sobrevivência do recém-nascido nas melhores condições possíveis ${ }^{(1)}$. Para exemplificar, tem-se o advento da implantação do método Mãe-Canguru, no qual favorece o contato pele a pele, como uma nova alternativa ao cuidado neonatal convencional para bebês de baixo peso ao nascer, propondo-se sua aplicação nas unidades neonatais, passando às "unidades canguru" - alojamento conjunto, e, após a alta hospitalar, nos ambulatórios de seguimento(2-3).

A Unidade de Internação Neonatal (UIN) surge como um espaço destinado para tratamento de RN's prematuros ou que apresentem algum tipo de problema ao nascer. Em razão da especificidade da clientela, bebês extremamente vulneráveis, as UIN são dotadas com aparelhos e equipamentos indispensáveis para o cuidado do pequeno paciente. Além do aparato tecnológico, existe a equipe multiprofissional especializada, capacitada e voltada para a humanização da assistência proporcionando um ambiente terapêutico satisfatório ao RN.

As UIN são divididas em diversos níveis de complexidade, em alto, médio e baixo risco. Nas unidades de baixo e médio risco, são acolhidos os recém-nascidos que necessitam de cuidados intermediários e, via de regra, são a termo, com padrões fisiológicos considerados dentro da normalidade. As unidades de alto risco são destinadas a receber neonatos que necessitam de cuidados intensivos, como: prematuros, anoxiados, cardiopatas, portadores de malformações, com incompatibilidade de $\mathrm{ABO} / \mathrm{Rh}$ e aqueles que necessitam de suporte ventilatório, como Pressão Positiva continua nas vias aéreas (CPAP) e respirador artificial ${ }^{(4)}$.

Neste cenário, o RN permanece dias ou meses na tentativa de sobreviver, recuperando-se do estado crítico de saúde ou ganhando peso para, finalmente, ser aconchegado nos braços e sob os cuidados maternos. Para a mãe, o nascimento de um filho pode ser considerado um evento fisiológico e emocional, permeado por sonhos, expectativas e ansiedades. Contudo, não acontecendo como previsto, mas com um parto complicado ou prematuro, ou ainda uma cesariana não programada ou outra intercorrência, as prioridades são revertidas e situações que indiquem o encaminhamento do RN à UIN concorrem para que o binômio mãe-filho seja separado, por pouco ou muito tempo, causando situações de estresse, de trauma para a família e especialmente para a mãe que, em alguns casos, se considera culpada. Ressalta-se que tal fato pode estar relacionado a problemas de ordem física ou emocional que o neonato apresente, isto porque se consideram responsáveis por sua vinda ao mundo e por tudo de mal que a ele possa acontecer ${ }^{(5-7)}$.

O primeiro contato dos pais com a Unidade de Internação causa espanto e surpresa por dois motivos, primeiro por ter uma gama de equipamentos ligados ao seu filho e segundo pelo fato de estar todo este aparato voltado para salvaguardá-lo. Isto ocorre porque, para os pais, a UIN representa um misto de esperança e de medo. Esperança, por saber em que é um local preparado para atender melhor seu filho e aumentar as chances de sobrevida, e medo por conhecerem riscos que seu bebê está correndo. Razão tem ao se lembrar que na UTI-Neonatal são no mínimo três os pacientes: o recémnascido, a mãe e o pai. A visão de um bebê extremamente doente, cercado de cuidados e de aparelhos, pode ser dolorosa para os pais e certamente influenciará na qualidade do contato inicial ${ }^{(8-10)}$.

Para o êxito do tratamento e brevidade do período de internação, é necessário o estabelecimento de vínculo afetivo entre os pais e o bebê, o mesmo acontecendo com a equipe que presta cuidados ao RN, tornando-se a relação impregnada de sentimentos de amor o que proporcionará respostas compensatórias em termos de bem-estar.

Nesta situação, a inserção do profissional de enfermagem torna o período de internação menos desgastante possível. Desse modo, é fundamental que, em especial no primeiro encontro deste trinômio, a enfermeira se faça presente, de forma genuína, portanto, solícita, perceptiva, pronta e disponível ${ }^{(4,13)}$. O ideal é o preparo inicial da mãe ao chegar à Unidade centrada no ambiente hospitalar e, especialmente, em relação ao quadro clínico e aparência de seu filho que, na maioria das vezes, não corresponde ao que foi idealizado no período gestacional. Para isso, cabe também ao pai a função de apoiar e dividir tal experiência com a mãe, já que é exposta à uma alteração hormonal fisiológica após o nascimento, o que influencia o estado emocional materno.

Dessa forma, faz-se necessário $o$ acompanhamento dos pais nesse período crucial e 
significativo. As dúvidas devem ser esclarecidas, sendo preciso que recebam informações em linguagem adequada no nível de compreensão dos pais, respeitando crenças e valores, não apenas sobre o estado de saúde do recém-nascido, mas também a respeito dos equipamentos, procedimentos e rotinas próprias da UIN para que sintam-se apoiados, valorizados e não venham a se afastar da unidade e, conseqüentemente, do filho. Um dos profissionais da equipe de saúde indicado para minimizar esse impacto diminuindo a tensão é a enfermeira ${ }^{(4)}$.

A crença é a base da realização pessoal de cada indivíduo e um referencial que dá segurança e identificação às pessoas em momentos da vida, sendo incompatível com a ciência, porque a ciência exige estudo, enquanto a crença e os valores requerem credibilidade. Diferenciando do conceito de crenças e valores, compreende-se sentimento como sensibilidade, compreensão, percepção, como também aptidão para sentir ${ }^{(11-12)}$.

Em face dos aspectos que envolvem a díade mãe-filho no âmbito da UIN, entende-se que existe a necessidade do enfermeiro exercitar a comunicação eficaz com a família do RN, com ênfase na figura materna, para que os efeitos, porventura causados pelo ambiente da UIN, sejam minimizados e estas possam vivenciar o internamento do filho.

A assistência não deve ser direcionada priorizando as condutas técnicas operacionais, mas para o acolhimento, compreensão e participação dos pais nos cuidados necessários à recuperação do fillho. Cabe à enfermagem humanizar esta relação, evitando situações de impessoalidade, tornando-a aliada na busca de uma vivência menos dolorosa e estressante. A partir dessas considerações acerca da problemática que permeia a percepção da mãe do neonato no ambiente da UIN surgem as indagações: de que maneira as mães percebem o ambiente físico e tecnológico da UIN onde seus filhos estão internados? Quais as crenças e sentimentos das mães de RN internados em uma UIN?

Objetivou-se, com este estudo, conhecer o significado do ambiente da Unidade de Internação Neonatal para as mães dos recém-nascidos e identificar as crenças e os sentimentos das mães ante o recém-nascido internado em uma Unidade de Internação Neonatal.

\section{DESCRIÇÃO DO MÉTODO}

Trata-se de um estudo exploratório-descritivo, com abordagem qualitativa, que responde às questões muito particulares, pois corresponde a um espaço profundo das relações, dos processos e dos fenômenos que não podem ser reduzidos à operacionalização de variáveis ${ }^{(14)}$.

A pesquisa foi realizada na Unidade de Internação Neonatal (UIN) de um hospital público de grande porte em Fortaleza-CE, agraciado pelo Ministério da Saúde, com o título de "Hospital Amigo da Criança". A UIN está localizada no $4^{\circ}$ andar da referida instituição e conta com 25 leitos assim distribuídos: 7 para a Unidade de Médio Risco 1 (UMR), 6 leitos para a UMR 2, 6 leitos para a UTI 1 e 7 leitos para a UTI 2.

As informantes foram 11 mães de RN internados na UIN do referido hospital. O número de participantes foi definido no decorrer da pesquisa, tendo por base a saturação dos depoimentos. Os requisitos para a inclusão das participantes foram: ser mãe de um RN internado na UIN e aceitar sua participação no estudo de modo espontâneo.

A coleta de dados foi realizada nos meses de agosto e setembro de 2005. Optou-se pela técnica de entrevista semi-estruturada para coletar os dados de identificação e questionamentos acerca do ambiente da UTIN, as crenças e sentimentos das mães ante a internação do filho na UIN.

As falas das participantes foram transcritas na íntegra e lidas pelas pesquisadoras, e posteriormente organizadas e apresentadas em forma de temáticas. Após o término da coleta dos dados, foram realizadas exaustivas leituras das falas das mães, tornando-se possível analisá-las e categorizá-las a mercê das categorias empregadas para estabelecer classificações que podem ser utilizadas em qualquer tipo de análise em pesquisa qualitativa ${ }^{(14)}$.

Durante todo o desenvolvimento do estudo, esteve-se atenta ao que preconiza a Resolução no 196/ 96 do Conselho Nacional de Saúde - Ministério da Saúde ${ }^{(15)}$, que regulamenta a pesquisa envolvendo seres humanos, em que foram respeitados os aspectos éticos e também legais, assegurando os direitos das informantes, sendo identificadas por meio de letras. Para tanto, o projeto foi submetido e aprovado pelo Comitê de Ética em Pesquisa do Hospital, tendo o número do protocolo $070715 / 05$, assim como foi assinado o Termo de Consentimento Livre e Esclarecido.

\section{RESULTADOS E DISCUSSÕES}

Conhecer a história do recém-nascido e seu estado de saúde ao nascer são dados importantes, pois indicam os cuidados imediatos necessários e conseqüentemente a urgência do encaminhamento à 
Unidade de Internação Neonatal e relevância da presença da mãe na unidade. Entretanto para prestar uma assistência humanizada ao recém-nascido e seus pais é preciso conhecer as crenças e sentimentos da mãe em relação à internação do filho em ambiente da UTIN. As falas mais significativas das mães serão apresentadas, após terem sido agrupadas segundo as categorias que emergiram: Significado do ambiente da Unidade de Internação Neonatal. Orientações recebidas x Aparato tecnológico. Sentimento em relação ao internamento de seu filho na UIN.

\section{Significado do ambiente da Unidade de Internação Neonatal}

A Unidade de Internação Neonatal introduz o bebê em um ambiente inóspito, em que a exposição a ruídos, luz intensa e contínua, bem como procedimentos clínicos invasivos são constantes nessa rotina. $\mathrm{O}$ tratamento altamente especializado, do qual depende a sobrevivência do recém nascido, instaura vários desafios no âmbito familiar e profissional ${ }^{(16)}$. Assim, é relevante o significado do ambiente da UIN vivenciado e descrito pelas mães como um local envolto de tristeza e medo, mas necessário para o tratamento do filho.

Achei normal [...] não senti nada... (M, M2).

Tristeza, eu comecei a chorar... (M3, M4).

Com base nas suas características intrínsecas, o ambiente da UIN carrega consigo um estereótipo e uma idéia de sofrimento. Desta forma, entrar na UIN significa, muitas vezes, para a mãe, um momento de angústia. Ressalta-se que, das mães entrevistas, somente uma já havia tido a experiência de internamento do filho em uma unidade de terapia intensiva neonatal e as demais estavam passando pela primeira vez por esta situação.

Estou preocupada, nunca tinha passado por isso... Eu achei ruim a separação [...]. Desgosto (M3, M4, M9).

Eu fiquei emocionada em ver aquelas crianças tudo dentro da incubadora, a gente quer pegar e não pode, é muito espremido (M5).

A rotina de uma Unidade de Internação Neonatal é desgastante, pois é um local no qual os profissionais convivem diariamente com a situação de morte iminente do recém-nascido e com a presença constante dos pais, que reconhecem a fragilidade da situação de seu filho. Essa situação pode implicar diretamente na conduta profissional, dificultando o modo de atuar ${ }^{(17)}$. Assim sendo, prioriza-se a sobrevivência do bebê, por isso a mãe pode e é aconselhável que faça parte do cuidado, sendo informada e esclarecida suas dúvidas.

Diante disso, o enfermeiro pode utilizar o momento da internação para que os pais aprendam mais sobre o crescimento e o desenvolvimento dos filhos, provocando, dessa forma, mudanças positivas, amenizando o estresse e potencializando a experiência ${ }^{(18)}$. Para tanto, o profissional deve buscar acolher a mãe no momento da chegada à Unidade de maneira atenciosa, fornecer informações, esclarecer dúvidas, incentivá-la à manutenção do vínculo, deixando-a ciente da realidade que acompanha a situação clínica do bebê. Quando a mãe recebe suporte da equipe de saúde, esta vai se adaptando à rotina do ambiente, desenvolve o cuidado e desmistifica a percepção acerca da fragilidade do recém-nascido na Unidade de Terapia Intensiva Neonatal.

Em relação ao modo como foram recebidas ao chegarem à UIN, quatro mães informou o sentimento de carinho e atenção e sete referiram a necessidade de comunicação/informação, como tambéma disponibilidade e sensibilidade individual dos profissionais. A maioria das mães gostaria de obter informações acerca do estado de saúde do filho e do suporte tecnológico existente na unidade antes do primeiro contato com o ambiente.

Eu fui recebida com carinho, amor, com muita atenção, todo o apoio (M1, M11).

[...] fui bem recebida, eles são bem educados, falam com a gente bem (M2, M4, M10).

A presença da mãe com o filho é essencial na UIN, sendo necessária uma equipe multiprofissional no atendimento do binômio mãe-filho, a fim de facilitar, estimular e proporcionar a formação do vínculo, promovendo uma assistência que contemple questões biológicas, psicológicas e sociais, o que nos faz refletir sobre a responsabilidade de cada ação, nos gestos, na comunicação, envolvendo cada palavra ${ }^{(19,20)}$.

Que alguém chegasse e me dissesse como estava o meu filho antes de eu pegar ele, ver ele ali, do jeito que ele estava; com mais atenção (M3, M5). 
A gente entra para saber como é o estado dele, então explicar como é que ele está [...] informassem e explicassem tudo (M6, M7, M8, M9).

$\mathrm{O}$ cuidado de Enfermagem ao RN e à família, com a devida competência, ética e sensibilidade é essencial no ambiente da $\operatorname{UIN}^{(6)}$. Foi possível notar nos relatos das mães o fato de que os profissionais não se identificam, haja vista que o enfermeiro como um dos profissionais capacitados para minimizar a tensão emocional da família, poderia ter uma atitude de escuta ativa e presença efetiva, de modo a permitir a verbalização das dúvidas e angústias. Assim, faz-se necessário que a mãe, como a pessoa mais próxima do recém-nascido, seja informada dos procedimentos terapêuticos realizados, para que se sinta apoiada e menos ansiosa. A prática assistencial prestada à mãe nesse momento é importante para a confiança entre ela e o profissional visando à humanização da assistência em UINs.

[...] Eu perguntei às meninas que trabalham lá, que ficam com ela. Ninguém chegou e se identificou para falar comigo, me explicar nada (M11).

Nesse sentido, a recepção dos pais que chegam à UIN pela equipe de Enfermagem de forma individualizada, considerando o nome da mãe, localizando e acompanhando até a incubadora, incentivando o toque, as palavras de carinho para com o bebê, portanto fazendo-se presente utilizando a empatia e o contato visual para com o $\mathrm{RN}$ e seus pais. Essas atitudes importantes para que os pais possam sentir-se acolhidos e participem do cuidado ao RN.

\section{Orientações recebidas x Aparato tecnológico}

O desconhecimento da terapêutica apresentase como gerador de estados de perturbação e nervosismo para a mãe ao presenciar o filho submetido a um tratamento diferente do contexto vivenciado diariamente. Portanto, torna-se relevante a orientação sobre os procedimentos realizados com o $\mathrm{RN}$, bem como em relação ao aparato tecnológico que o cerca. Acredita-se que o cuidado a ser implementado na UTIN necessita ser exercido e vivenciado em sua totalidade, na tentativa de reduzir manuseios excessivos que possam comprometer o bem-estar do bebê, provocando nele manifestações de estresse, dor, alterações fisiológicas e comportamentais ${ }^{(6,21)}$.

Com o objetivo de conhecer o significado da
UIN foi percebido que durante o acesso das mães à unidade, surgiu a necessidade de enfrentamento de uma gama de equipamentos que cercam o filho, juntamente com a intensa movimentação de profissionais e a incerteza do estado de saúde do filho, revelando a necessidade de um suporte que o ajude na tessitura desta relação que se inicia de maneira muito instável e conflituosa. Daí a importância da orientação adequada para com a mãe no momento da admissão do filho à UIN, proporcionando-lhe um conhecimento prévio do contexto atual que vivenciará ${ }^{(22)}$.

A enfermeira me explicou bem direitinho o que é que ele estava tomando ... (M2).

A moça que trabalha lá, eu não sei como é, acho que ela cuida dos bebês. Não sei se é a enfermeira, ela não me disse (M1, M5, M6).

Na maioria das vezes, durante a rotina da UIN, as prioridades são voltadas para os cuidados com o $\mathrm{RN}$ e a mãe passa a ser vista como uma figura presente na unidade, mas distante da equipe. A mãe tende a apresentar dificuldades de expressar suas dúvidas, inquietações, dificultando o relacionamento com a equipe de saúde e, conseqüentemente, o possível déficit no vinculo mãe-filho que deveria ser fortalecido.

[...] eu cheguei assim tímida, só quem conversou comigo foi a moça que cuida dele, mas eu também não perguntei. Mas da segunda vez eu procurei e perguntei, mas ninguém chegou para me informar nada (M8) .

São evidentes as peculiaridades existentes na internação de um filho na UIN, como a situação clínica do $\mathrm{RN}$, o ambiente físico cercado de equipamentos, o quantitativo elevado de profissionais, termos técnicos desconhecidos, dentre outras que impõem estresse e podem conferir ao local uma aparência de desumanidade, ao mesmo tempo em que o desconhecimento e a nãoinformação adequada proporcionam um momento de tensão e indiferença para com a mãe.

Fiquei um pouco mais assustada porque ele estava cheio de aparelhos aqui na cabeçinha, todo medicado [...] (M5).

Quando eu vi ele lá, respirando pelo aparelho, aquilo me deixou louca (M8). 
É crucial que as mães estejam conscientes do estado de saúde do filho, mas também sobre os equipamentos existentes e os procedimentos que são realizados para que seja preservada a saúde do $\mathrm{RN}$, devendo ser, portanto esclarecido as dúvidas e os medos, assim como o respeito em preservar crenças, buscando a formação do vínculo de apoio na tríade equipe de assistência-mãe-RN, com o intuito de proporcionar ajuda para que as mães se achem úteis, capazes e importantes no cuidado, e não venham a se afastar da unidade, conseqüentemente, do filho.

\section{Sentimento em relação ao internamento de seu filho na UIN}

$\mathrm{Na}$ gestação, a mulher imagina um bebê saudável, perfeito para os padrões da sociedade, sem problemas de saúde e, ao se deparar com uma realidade diferente, fica envolvida por várias emoções. As falas refletem a inquietação das mães em relação ao estado de saúde do filho e da situação que estão enfrentando. O medo e a preocupação com o $\mathrm{RN}$ produzem sentimentos negativos na mãe, que podem afetar a formação do vínculo mãe-filho. Por mais que demonstrem confiança, pensamentos negativos permeiam o cotidiano.

Foi ruim por um lado e bom por outro. Para mim foi ruim porque eu não vou poder ir embora com ele e foi bom porque ele estava doente e precisava que isso acontecesse. Se não fosse lá onde é que ele iria ficar para se tratar? (M5, M8).

Fiquei preocupada dele não estar bem [...] com uma infecção [...] estar ali na incubadora, com aquelas luzes, indefeso [...] eu não estou dando de mamar (M7, M11, M10, M9).

O desconhecimento das mães leva à necessidade da fé em Deus e a conformação com o estado experimentado, o que torna muitas vezes tarefa difícil, a compreensão da realidade, derivando um misto de impotência e angústia. As crenças reforçam comportamentos e atitudes, assim como fortalece o desejo de recuperação e cura dos filhos. No momento de fragilidade, tristeza e angústia geradas pela condição do internamento na Unidade, a busca do divino intensifica-se no sentido de manter viva a esperança. Em momentos difíceis o ser humano apega-se à cultura, à fé, na procura incansável de força.

As mães verbalizam fatos que originam sentimentos de dor e preocupação, sendo a tristeza conceituada como falta de alegria, melancolia, mágoa, pesar, pena, piedade. O medo significa o sentimento de viva inquietação ante a idéia de perigo real ou imaginário de ameaça, pavor, temor, receio ${ }^{(22,23)}$.

[...] eu tenho fé em Deus que eu nunca mais vou passar por isso que é muito, muito dificil ... (M2).

No primeiro momento quando eu fui vê-lo eu fiquei muito deprimida. [...] O primeiro momento é muito difícil, quase eu não agüento ficar lá (M8, M9).

Assim, tem-se a importância do envolvimento dos profissionais com as mães que estão com seus filhos internados, necessitando de orientações em relação ao ambiente e sua estrutura física, seus direitos e deveres como mãe. Ressalta-se, ainda, que um dos principais motivos que facilita a presença da mãe na Unidade Neonatal é o livre acesso a elas permitido. $\mathrm{Na}$ UIN não há horário fixo para a visita da mãe à criança, visando à atenção humanizada conforme orientações do Ministério da Saúde ${ }^{(24)}$. Portanto, há de se promover um acolhimento das necessidades intersubjetivas da díade mãe-filho, assim como a permanência da mãe na unidade, facilitando a comunicação e interação da mãe com o profisssional, propondo esclarecimentos e/ou minimizando sentimentos negativos e crenças que o ambiente da unidade de internação possa induzir.

\section{CONSIDERAÇÕES FINAIS}

As vivências desse estudo não esgotaram, mas reforçaram as crenças e sentimentos maternos em relação ao recém-nascido em uma Unidade de Internação Neonatal considerado como fato traumático originando barreiras no relacionamento entre a mãe e o recém-nascido. Fazem-se relevantes estudos que priorizem a humanização do cuidado, por meio da humanização na assistência prestada.

Em virtude da falta de informações, a mãe raramente desenvolve autonomia em participar do cuidado do filho que, fragilizado e monitorado por aparelhos, necessita de intensa atenção e empatia, sentimentos imprescindíveis para quem deseja ser cuidado e não somente tratado.

Cabe ao profissional de saúde que atua na área de Neonatologia repensar a prática assistencial proporcionada às mães dos recém-nascidos internados. 
O profissional deve acompanhar a interação da mãe com o ambiente da Unidade, mostrar-se presente, capacitado e disponível para ajudar e esclarecer dúvidas, sentimentos e crenças. Deve identificar-se para que seja formado um vínculo que facilite a comunicação entre a mãe e a equipe cuidadora da Unidade a fim de fornecer um acompanhamento ao recém-nascido e à mãe, que deve estar presente, sendo vista como um elemento somatório na recuperação do neonato.

Conclui-se a necessidade de sensibilização dos profissionais da equipe de saúde na Unidade de Terapia Intensiva Neonatal, em especial a Enfermagem, desenvolvendo uma visão diferenciada sobre o binômio mãe-filho para que estes, apesar da situação vivenciada que permeia a internação do neonato e do ambiente de alta tecnologia, possam estar melhor, enquanto experimentam esta separação, que pode se estender a dias, semanas ou meses.

\section{REFERÊNCIAS}

1 Ramos JLA. Âmbito e finalidades da pediatria neonatal. In: Marcondes E. Pediatria básica. $5^{\text {a }}$ ed. São Paulo: Sarvier; 1991.p. 259-60.

2 Venancio SI, Almeida H. Método mãe canguru: aplicação no Brasil, evidências científicas e impacto sobre o aleitamento materno. J Ped. 2004; 80(5 Supl): S173-80.

3 Mota LA, Sá FE, Frota MA. Estudo comparativo do desenvolvimento sensório-motor de recém-nascidos prematuros da unidade de terapia intensiva neonatal e do método canguru. RBPS. 2005;18(4):191-8.

4 Campos ACS, Silveira IP, Cardoso MVLML. Transpondo a vidraça: a visão do pai na unidade de internação neonatal. Rev Enferm Atual. 2004;4(19):19-23.

5 Rolim KMC, Campos ACS, Oliveira MCC, Cardoso MVLM. Sensibilizando a equipe de enfermagem quanto ao binômio mãe-filho. Rev Enferm Atual. 2004;4(21):30-3 .

6 Campos ACS. O significado de ser mãe de um recémnascido sob fototerapia: uma abordagem humanística [tese]. Fortaleza (CE): Universidade Federal do Ceará; 2003.

7 Mota MGC. O ser doente no tríplice mundo da criança, família e hospital: uma descrição fenomenológica das mudanças existenciais. Florianópolis; 1998.

8 Maldonato MT. Como cuidar de bebês. $3^{\mathrm{a}}$ ed. São Paulo: Saraiva; 1996.

9 Oliveira ME. Assistência de enfermagem ao recémnascido com icterícia fisiológica. In: Oliveira ME, Monticelli M, Bruggemann, organizadoras. Enfermagem obstétrica e neonatológica; textos fundamentais. $2^{\mathrm{a}}$ ed. Florianópolis: Cidade Futura; 2002. p.298-304.
10 Mendes ENW. Cuidados de enfermagem em terapia intensiva neonatal. In: Miura E, Procianoy RS. Neonatologia, princípios e prática. $2^{\mathrm{a}}$ ed. Porto Alegre: Artes Médicas; 1997.p. 17-20.

11 Dilts R. Crenças: caminhos para a saúde e o bem-estar [acesso em 2005 Mar 14]. Disponível em: http:// www.golfinho.com.br/livros/liv026.htm.

12 Bastos AL de F. Dicionário didático da língua portuguesa. São Paulo: Didática Paulista; 2003.

13 Paterson JG, Zderad LT. Humanistic nursing. New York: National League for Nursing; 1988.

14 Minayo MCS. Ciência, técnica e arte: desafio da pesquisa social. In: Minayo MCS, organizadora. Pesquisa social: teoria, método e criatividade, $21^{\mathrm{a}}$ ed. Petrópolis: Vozes; 2002. p. 9-29.

15 Ministério da Saúde(BR). Conselho Nacional de Saúde. Diretrizes e normas regulamentadoras de pesquisa envolvendo seres humanos. Resolução $\mathrm{n}^{\circ} 196$, de 10 de Outubro de 1996. Brasília; 1996.

16 Lamego DTC, Deslandes SF, Moreira MELM. Desafios para a humanização do cuidado em uma unidade de terapia intensiva neonatal cirúrgica. Ciênc Saúde Coletiva. 2005;10(3):669-75.

17 Aguiar IR, Veloso TMC, Pinheiro AKB, Ximenes LB. O envolvimento do enfermeiro no processo de morrer de bebês internados em Unidade Neonatal. Acta Paul Enferm. 2006;19(2):131-7.

18 Esteche CMGCE. Diarréia aguda na infância: aspectos epidemiológicos de um hospital distrital em Fortaleza. [dissertação]. Fortaleza (CE): Universidade Federal do Ceará; 2003.

19 Saccuman E, Sadeck LSR. Assistência aos pais de recém-nascidos de risco. In: Leone CR, Tronchin DMR. Assistência integrada ao recém-nascido. São Paulo: Atheneu; 1996. p.35-46.

20 Wayhs RI, Sousa AIJdeS. Estar no hospital: a expressão de criança com diagnóstico de câncer. Cogitare Enferm. 2002;7(2):23-6.

21 Rolim KMC, Cardoso MVLML. O discurso e a prática do cuidado ao recém-nascido de risco: refletindo sobre a atenção humanizada. Rev Latino-am Enferm. 2006. 14(1):85-92.

22 Ferreira ABH. MiniAurélio século XXI: minidicionário da língua portuguesa. $7^{\mathrm{a}}$ ed. Rio de Janeiro: Nova Fronteira; 2002.

23 Abreu ASGT, Souza IEO. O pai à espera do parto: uma visão compreensiva do fenômeno. Rio de Janeiro: Ed. do Autor; 1999.

24 Brasil. Portaria ${ }^{\circ} 072$ de 02 de Março de 2000 [acesso em 2000 Mar 04]. Disponível em: http:// portal.saude.gov.br. 